\title{
The Contrastive Study of Igbo and English Denominal Nouns
}

\author{
Aloysius U. Umeodinka \& Christian E. C. Ogwudile \\ http://dx.doi./org/10.4314/ujah.v18i2.24
}

\begin{abstract}
Language is an indispensable tool in the affairs of human beings. It is a system of arbitrary and conventional symbols by which humans communicate. Language is the central object of study in linguistics. In the morphological study in linguistics, Denominal nouns are words formed from nouns. Linguistics, through its branch, Applied Linguistics, has been of immense help in the teaching of a second language and in analyzing learner's errors. The teaching of nominalization has not been all smooth for an Igbo second language learner of English language. That is why this study is set to contrast English and Igbo Denominal nouns. The objective is to find out the similarities and differences between the nominalization process in Igbo and that of the English language. Also, the study will seek to know how the findings will contribute to the enhancement of the teaching of English Denominal nouns to the Igbo learning English as a target language. A descriptive approach is used in the study. The theory of Contrastive Study propounded by Robert Lado in 1957 guides the study. The study discovers that unlike English, Igbo language uses syllable reduction, reduplication and noun-agent and noun object combination. Also, it discovers that both English and Igbo employ both prefixation and suffixation in nominalization. Another discovery is that since there exist more irregularities in the English morphological process than in Igbo, the pedagogical attention for the Igbo learner should be centred on the majority of the words and their specific patterns in the irregularities.
\end{abstract}




\section{Introduction}

Language occupies a pivotal position in the affairs of human beings. There is hardly any facet of life that does not engage language in one way or the other. Linguistics is a discipline that studies language with the approach of science. It studies language to explain how it works, examines its nature, features and structure-all to the benefit of mankind. The linguistic study of language enables us to analyse and understand the nature of the complex structural components of a language, which include phonology, morphology, syntax and semantics.

Besides, linguistic study provides some important evidence for language teaching decisions. It plays an important role in the determination of the content of learning. Many decisions the classroom teacher takes on a regular basis, some prepared, some off the cuff, about his teaching methods and techniques are taken for him by the people who produced the teaching materials that he uses. These decisions by people who generate teaching materials have the goal of the improvement of learning. The study of linguistics is of great assistance in articulating the implications of many current and proposed practices in language teaching. The pieces of evidence from linguistics are looked upon for solutions to the problems that are faced in language teaching. It suffices to say that the significance of linguistics is traceable to the door steps of increasing a teacher's awareness of language as it makes him a more competent and better teacher. Through its branch of applied linguistics to which contrastive study belongs, linguistics, as a science, deals with practical applications of the findings of theoretical linguistics in such areas as language teaching, methodology and speech therapy. 
It is against this backdrop that this study is about the Contrastive Study of English and Igbo Denominals. Contrastive study or Contrastive analysis is a practice-oriented linguistic technique that seeks to describe or compare the similarities and differences between a pair of languages. The word, Denominals, refers to both the process and the nouns formed from nouns. The objective of the study is to find out how the morphological processes of English and Igbo Denominals are similar and different from each other. The study is further motivated by the desire to establish how the findings can be used to help the learner of English as a second language. The approach the study uses is the descriptive type. The theory of Contrastive Analysis propounded by Robert Lado in 1957 anchors the investigation.

The work is organized in sections. The first section, the introduction, prepares the mind of the reader about the subject matter and motivation for the study. The second section, the literature review, takes another look into some published works that have bearing on the topic of investigation. Research methodology takes up section three, to further reveal how the corpora for the investigation and analysis were collected. Section four is devoted to data presentation and analysis. The summary of findings and conclusion occupy section five.

This work is done with the expectation to create some awareness about the morphological processes of English and Igbo in the area of forming nouns from nouns. Many people are expected to take the full knowledge from this work. The work hopes to bring about some changes and improvement in the teaching and learning of the English language as L2. 


\section{Literature Review}

The views of experts and notable people involved in language are re-visited here.

\section{On the Issue of the Explanation of Language}

According to "Merriam-Webster's Learner's Dictionary", language is defined as the system of words or signs that people use to express thoughts and feelings to each other; any one of the systems of human language that are used and understood by a particular group of people. The key point in this definition is that words and signs take the form of a group of things that is connected or ogranised and that work together (that is, as a system). Another point is that it is of benefit to human beings, because they use it to make known their thinking and how they feel. Also implied in this definition is that exchange takes place when language is used, because "feelings and thoughts" are expressed to each other.

Agbedo (2015:14) gives what he calls a general view of language, as a "human system of communication that uses arbitrary signals, such as voice sounds, gestures, or written symbols." This definition resembles the previous one as both see language as a system and as a system that is used or is beneficial to human beings. Both also talk of signs. But the dictionary definition, unlike this one, does not give examples of what constitutes the signs. And unlike the latter, the former specifies that it is a group of people that use language.

In the words of Sapir (1921:8), language is "a purely human and non-instinctive method of communicating ideas, emotions, and desires by means of voluntarily produced symbols". On their part, Bloch and Trager (1942:5) are of the view that language is "a 
system of arbitrary vocal symbols by means of which a social group cooperates". One major difference between these two definitions is that the symbols are said to be arbitrary in Bloch and Trager's definition as against that of Sapir which is only voluntarily produced. The two definitions have an implication of doing things together in the form of exchange. This is made clear in the use of the words "cooperate" and "communication". The definition by Bloch and Trager (1942) do not include the fact that individuals also make use of language. Our own definition in this work is that, "language is a system of humanly produced sounds in the form of agreed symbols which are used by individuals or group of people for the purpose of communicating ideas, thoughts and feelings.

Turning to linguistics, Okolo and Ezikeojiaku (1999) present the definition of linguistics by Crystal (1969:27) as "the scientific way of studying language-or perhaps it should be languages, to emphasize the fact that we mean both language in general as well as languages in particular'. They go ahead to say that linguistics performs two main tasks as follows": The first is being bothered only about the study of particular languages as ends in themselves. This responsibility is undertaken by linguistics so as to be able to generate wholesome and precise descriptions of such languages. The second task is that linguistics embarks on the study of languages as an aim to attain other purposes, in order to be in a vantage position to obtain information about the nature of language in general. Their view is that the interest of the linguist is on the way language works, and he gets to know this by taking up specific languages for a thorough and objective study. 
According to "Merriam-Webster's Learner's Dictionary", language is defined as the system of words or signs that people use to express thoughts and feelings to each other; any one of the systems of human language that are used and understood by a particular group of people. The key point in this definition is that words and signs take the form of a group of things that is connected or ogranised, and that work together (that is, as a system). Another point is that it is of benefit to human beings, because they use it to make known their thinking and how they feel. Also implied in this definition is that exchange takes place when language is used, because "feelings and thoughts" are expressed to each other.

Agbedo (2015:14) gives what he calls a general view of language, as a "human system of communication that uses arbitrary signals, such as voice sounds, gestures, or written symbols." This definition resembles the previous one as both see language as a system and as a system that is used or is beneficial to human beings. Both also talk of signs. But the dictionary definition, unlike this one, does not give examples of what constitutes the signs. And unlike the latter, the former specifies that it is a group of people that use language.

In the words of Sapir (1921:8), language is "a purely human and non-instinctive method of communicating ideas, emotions, and desires by means of voluntarily produced symbols". On their part, Bloch and Trager (1942:5) are of the view that language is "a system of arbitrary vocal symbols by means of which a social group cooperates". One major difference between these two definitions is that the symbols are said to be arbitrary in Bloch and Trager's definition as against that of Sapir which is only voluntarily produced. The two definitions have an implication of doing things together in the form of exchange. This is made clear 
in the use of the words "cooperate" and "communication". The definition by Bloch and Trager (1942) do not include the fact that individuals also make use of language.

Our own definition in this work is that, "language is a system of humanly produced sounds in the form of agreed symbols which are used by individuals or group of people for the purpose of communicating ideas, thoughts and feelings.

\section{On the Relationship between Linguistics and Language}

Turning to linguistics, Okolo and Ezikeojiaku (1999) present the definition of linguistics by Crystal (1969:27) as "the scientific way of studying language-or perhaps it should be languages, to emphasize the fact that we mean both languages in general as well as languages in particular". They go ahead to say that linguistics performs two main tasks as follows": The first is being bothered only about the study of particular languages as ends in themselves. This responsibility is undertaken by linguistics so as to be able to generate wholesome and precise descriptions of such languages. The second task is that linguistics embarks on the study of languages as an aim to attain other purposes, in order to be in a vantage position to obtain information about the nature of language in general. Their view is that the interest of the linguist is on the way language works, and he gets to know this by taking up specific languages for a thorough and objective study.

Akmajian, Demers, Farmer and Harnish (2012) delve into the background assumptions that linguists make in their study of language. According to them, the most important assumption human language is rule-governed or operates by principles at all levels. They are saying that there is no language that has absence 
of systematic rules or principles dictating how pronunciation, word formation and grammatical construction should proceed along the line of established systems or rules or principles. The association of phrases with meanings and the use of language to communicate are all governed by important generalizations that can be expressed in rules. Akmajian, Demers, Farmer and Harnish (2012) go further to explain what linguists make reference to when they talk about rules.

According to them, the rules linguists formulate when they analyse language are descriptive rules. They explain that descriptive rules are rules that describe the actual language of some group of speakers and not some hypothetical language those speakers "should" make use of. They stress that what descriptive rules do are to express generalizations and regularities concerning various aspects of language.

They further explained that to be rule-governed is another way of saying that the study of human language has revealed numerous generalizations about and regularities in the structure and function of language. Yet, there is another assumption they attribute to linguists when they are describing language. They maintain that various human languages constitute a unified phenomenon. What this implies is that to undertake a general study of human language is possible and that the study of particular languages will reveal features of language that are universal. By universality, they mean that even though specific languages obviously differ from each other on the surface, but if we look closer we find that human languages are surprisingly similar. 
Linguistics, in its study, does not promote any standards of language use. All its work is done objectively using a scientific approach. The method of linguistic study is not only objective but also empirical. Being empirical is synonymous with applying the process of observation, description and explanation (Finch, 2000). He argues that by observing the way people use language, linguists, from there, are able describe language use. Then when all the data have been analysed, they will give an explanation. This explanation is about their effort to establish the underlying rules which speakers are following. The rule is about the internalized set of instructions in the way they construct and use language.

Wilkins (1972) gives the salient points about the major concentration of the works of linguistics. They include studying the human language faculty, developing theories to explain language behaviour, providing the most significant means for describing language, making the most accurate and comprehensive descriptions of languages available. He argues that linguistic evidence is one of the areas language teachers have to refer to while making language teaching decisions; it plays a vital role in the determination of the content of learning. The point Wilkins (1972) is putting across in this view is that the teacher has something to gain from the study of linguistics; that teachers often resort to evidence in linguistics in order to solve some language teaching problems. The kernel contribution of linguistics is to increase the person's understanding of the nature of language. Every linguist is sensitized to language and the complexity of language learning. 


\section{On the Relevance of Applied Linguistics}

In his view about the applications of the findings of theoretical linguistics, Umaru (2005) brings in applied linguistics which he says uses the findings and techniques of other areas of linguistic study to aid in a variety of practical tasks like language teaching. $\mathrm{He}$ postulates that applied linguistics is a term that embraces a wide variety of practical uses of linguistic theory and methodology in fields as varied as language teaching, speech therapy and translating. It has become clear from all these views that applied linguistics is useful to language teaching as a form of application into practical use of the findings of linguistics.

In his own view, Mekiliuwa (2008) defines applied linguistics as the field of linguistics that studies and proposes solutions to practical issues and problems related to language use. Continuing, he stresses that it is about the application of what we know about language, the way we learn it and the way and manner in which we use it to solve problems in the real world. One of the areas applied linguistics is made use of is in language acquisition and language teaching and learning. Mekiliuwa (2008) lists other areas Schmitt (2002) as topic areas of the concern of applied linguistics. They include the combination of language study with the following fields of study: the brain, cognition, culture, ideology, instruction, interaction, translation, writing, policy, technology, society, media and listening.

These points from Schmitt (2002) appear to have been subsequently expressed by Wilkins (1999:7) in his definition of applied linguistics, thus:

“...concerned with increasing understanding of the role of language in human affairs and thereby with providing the 
knowledge necessary for those who are responsible for taking language-related decisions whether the need for these arises in the classroom, the workplace, the law court or the laboratory".

Agbedo (2015) does not disagree with this view. Instead, he adds that it is in applied linguistics that the findings of linguistic theories and descriptions are taken over and applied directly to language teaching. Anozie (2007) enumerates what he thinks are the uses of applied linguistics. They include facilitating the acquisition of a language other than the person's mother tongue, formulating the actual teaching techniques and book production, awakening the teacher's consciousness of the need to present his materials in a manner different from the disinteresting, stereotyped description and vary it in accordance with the pupils' linguistic background, solving the practical problems of automatic or machine translation and exploitation of statistical techniques connected with the use of language.

Wilkins (1972) asserts that for many people, applied linguistics is synonymous with contrastive analysis. He proceeds to reveal that the person who founded Contrastive analysis was Robert Lado in 1957 through the publication of his book Linguistics Across Cultures. In it, Lado (1957) stresses that errors and difficulties that occur in learning and use of a foreign language are caused by the interference of our mother tongue. He maintains that when the structure of the foreign language differs from that of the mother tongue, it signifies the expectation of difficulties in learning and error in performance. In such a situation, learning a foreign language is tantamount to learning to subdue these difficulties. 


\section{Applied Linguistics and its Birth of Contrastive Analysis}

Through not only applied linguistics, Mekiliuwa (2008) argues, but also via the assumptions that linguistics has made about the nature of language and the language learning process, there exist some approaches that have traditionally been adopted in the teaching of a second language and in analyzing learners' errors. Two of those approaches include Contrastive analysis and Error analysis. He describes the former as one of the earliest approaches used in addressing the challenges of second language teaching, that what contrastive analysis does is to contrast two languages (the first language of the learner or the target language). The next step in the task, according to Mekiliuwa (2008), the purpose of this contrast is to identify some structural similarities and differences between the two languages.

On the relevance of Contrastive analysis, Agbedo (2015) maintains that it has unquantifiable advantages in teaching. According to him, the improvement of pedagogy is one of the concerns of contrastive analysis. In his view, it is contrastive studies that brings to light the differences between the mother tongue and the target language of the learners and so makes it possible to predict the difficulties that the learners will have. From there, what the learners have to learn is found out, including what the teacher has to teach. Consequently, the results of contrastive analysis are built into language teaching materials, tests and researches.

It is not only Agbedo (2015) that has mentioned the uses of contrastive analysis. Okorji and Okeke(2009) had earlier touched on the uses. They are of the view that the importance of contrastive analysis lies on the belief that the first language (L1) has a very big effect, positive or negative, on the learning of the second or any other language. They argue that contrastive analysis involves a 
comparative description of the L1 and the L2 so as to ascertain the ways they are apart or resemble. According to them, similar systems in the two languages (L1 and L2) will enhance or help the learning of L2. What this means is that $\mathrm{L} 1$ removes difficulties or makes easy the learning of L2. But in the case of differences between L1 and L2, it may give rise to interference or place obstacle in the learning. They maintain that contrastive analysis occurs before the teaching could commence.

Anozie (2007) opines that applied linguists that have structuralist orientation are of the belief that learning a novel language involves the transfer of habits, in the course of which incorrect ones could be transferred. Reacting to this view, Anozie (2007) quotes Bell (1973) as asserting that, "...all language teachers and language learners are aware learners make mistakes". Reporting the views of H.C. Dulag and M.K. Burt (1974), Anozie (2007) explains that they say that one cannot do without goofing in learning a language. It for this reason that he advises that efforts should be geared towards eschewing errors that could be learnt or transferred from usually the mother-tongue to the target language. It is for this reason, in his view, that applied linguists make use of contrastive analysis as one of their important tools for the teaching of language.

\section{On the Involvement of Morphology}

In teaching, for instance, morphology, in language studies, according to Akmajian, Demers, Farmer and Harnish (2012), poses the following questions about the nature of words: what are words? What are the basic building blocks in the formation of complex words? How are more complex words built up from simpler parts? How is the meaning of a complex word related ton meaning of its 
parts? How are individual words of a language related to other words of the language? Prior to these questions, they have given the definition of morphology as the subfield of linguistics that studies the internal structure of words and the relationships among words.

Anagbogu, Mbah and Eme (2010) are of the view that morphology is about the shape or forms of words and their meanings. Like Akmajian, Demers, Farmer and Harnish (2012), they pose their own questions about the demanding problems of morphology, thus: What is the smallest meaningful unit of language? How is such a unit established in general and for each word? What is the link between distinctive or contrastive speech sounds set up in phonology and the way they vary or are realized in particular words?

Prasad (2014) postulates that there are three aspects of morphology: derivation, inflection and compounding. According to him, derivational morphology derives one lexeme from another. His example is the derivation of "development" from the verb "develop" by the attachment of the suffix "-ment". He goes on to say that morphology and semantics are related in the area of being involved in meaning. He maintains that while semantics determines the logical form or logical meaning of sentences, morphology concerns itself with the meaning of word components. Otagburuagu, Okwor, Ngonebu, Orabueze and Ogenyi (2012) define morphology as the study of the elements that make up the structure of words. According to them, morphemes are the parts of words that are meaningful because they change meanings, but cannot stand on their own. It is a minimal unit of language. To them, morphology shows the various ways in which words are 
formed and modified in a particular language to determine their meanings. Knowing how words are formed, helps us to identify the meanings of unfamiliar words, understand how new words are introduced into a language and discover the origin/etymology of the words already in use. In their view, two types of morphemes exist, free morphemes and bound morphemes. They have two categories of free morphemes-lexical and functional morphemes. Their two types of bound morphemes are derivational and inflectional morphemes.

From Crystal (1991:252), a morphological process involves morphemes. It is "any of the formal processes or operations by which the forms of words are derived from stems or roots. E.g. reran is derived from the root run by two morphological processes, one adding re- (run $\rightarrow$ rerun), the other changing $u$ to $a$ (rerun $\rightarrow$ reran)". Crystal (1991) explains an affix as any element in the morphological structure of a word other than a root. The process of adding an affix is affixation. Types of affixes are prefixes, which come before the form to which they are joined; suffixes are the ones that come after; and infixes are the ones inserted within it. Other types are circumfixes and superfixes.

\section{On Denominal Nouns}

In his view "Deverbal" is a process by which words or other classes are derived from verbs, e.g. action and actor are deverbal nouns. Crystal (1991) defines Denominal as a process by which words of other classes are formed from nouns. Also of the words formed: e.g. beautiful is a Denominal adjective, whereas beauty is a Denominal noun. That is noun formed from noun. 
Emenanjo (2015) talks about morphological processes through Nominalization, terms used for the multiplicity of processes which result in the creation of nouns and nominals. The nouns and nominals so formed have a wide variety of morphological and structural shapes with elements from other primary and functional categories. He maintains that affixation, reduplication and tones alone constitute the common prolific processes for nominalization in the Igbo language. He itemized sources of nominalization include nouns resulting in Denominal nouns, verbs resulting in deverbal or deverbative nouns, phrases/noun or verb phrases resulting in de-phrasal nouns, sentences resulting in de-sentential nouns and acronyms as nominals. His examples of Denominal nouns in Igbo include anx (meat, animal) -anxmanx (animal kingdom or creatures), mpe( smallness) -mperimpe (shrededness), nka (old age)--- nkarinka (tatteredness/ worthlessness), ogo(height, upness)-ogologo (length), Xwa (world)--- xwatxwa (eternity, world without end).

Emenanjo (2015) goes further to disclose the types of Denominal nouns formed through reduplication, e.g. aga (side, direction)--aglga (extreme or tortuous side away or direction), eri (thread)---eriri (rope or twine), ihie (day or light)---ehihie (afternoon), ike (strength)--- ikike (authority), qdx (tail)--- Qdxdx (last/ end(in a series), etc.

Through the internet on-line research, a Denominal noun is defined as a noun that is formed from another noun, usually by adding a 
suffix, such as villager (from village), New Yorker (from New York), booklet (from book), lectureship (from lecture), librarian (from library). Other examples are Nixonite, bicycler, and saxophonist formed from concrete nouns like Nixon, bicycle and saxophone by derivation. Here, it is explained that Denominal nouns can also have contextual expressions. "ant", as a morpheme, can be used productively to generate words denoting substances and persons, respectively, as evidenced by the following examples, disinfectant, repellant, consultant, accountant and defendant (http://www.theenglishusa.tk/2014/01/denominal nouns.html).

Murthy (2007) gives a good number of abstract nouns in English formed from common nouns. They are as follows: act-action, baby-babyhood, beggar-beggary, coin-coinage, agentagency, bond-bondage, infant-infancy, man-manhood, owner-ownership, king-kingship, etc.

A research work in 2016 on The Contrastive Analysis of English and Igbo Denominal Nouns by a team of researching students (Onwuka, Obiogbolu, Ogugua and Onuekwusi) gives an array of Denominal nouns and their formation processes in the two languages. Their work's objective is to isolate the similarities and differences in the two languages and make some predictions on their effects on the teaching of a second language, English. They define Denominal noun as a noun generated from another noun usually by add"ing suffix. Their research is a corpus-based contrastive analysis. They exhibit examples of Denominal nouns formed through the use of agentive prefix "o", instrumental prefix " $\mathrm{n}$ ", and agentive negative "e". Also included in their copious examples include the Denominal nouns formed through syllable reduction and through noun-agent and noun-object combination. 
These examples will surface in our analysis, as they are too many to outline here.

Expressing some teaching problems that can be solved with contrastive analysis and possibly common with morphological areas of language study, Oluikpe (1978) is of the view that a major weakness in the teaching of English in Nigeria is that we do not teach with the aim of solving the language problems peculiar to linguistic communities in the country. Praising the scarcely gotten efforts of the sort, he says that the attempt by the Imo State Government of Nigeria to design English primary textbooks for Imo State pupils was therefore, a step in the right direction. He stresses that such steps are supposed to be practical in their pedagogic content and also be based on the contrastive studies of the mother tongue with the target language. He emphasizes that text books relating to second language teaching should be produced with the inclusion of linguistic base; it should not fail to address the peculiar needs of the learners. With this assertion, he stresses the need for the contrastive studies of English with different Nigerian languages. He goes on to give a list of the set of people to whom books on contrastive analysis of two languages, especially Nigerian languages, will be of immense use to: textbook authors, curriculum planners, teachers of English, students of English in institutions of higher learning. He makes it clear that the Igbo speakers of English are bound to encounter interference problems.

\section{Theoretical Framework}

The theoretical framework for this study is the Theory of Contrastive Analysis propounded by Robert Lado in his book Linguistics Across Cultures. The claim of the theory is that the 
errors and difficulties that occur in our learning and use of foreign language arise from the interference of our mother tongue. He maintains that whenever there is a divergence between the structure of a foreign language and that of the mother tongue there must be difficulty in learning and error in performance. The theory claims that learning a foreign language is synonymous with learning the existing difficulties. It claims that where the structures of the two languages are similar, no difficulty will be expected and there is no need for teaching; simple exposure to the language will be sufficient. Teaching will only be focused on those points where there are structural differences.

It is through the comparative study or contrastive analysis of the target language and the mother tongue that the differences between the two languages can be found out. It is this finding, according to the theory, that makes it possible to predict the difficulties the learner will encounter. The importance of this finding is that the results are built into language teaching materials, syllabuses, tests and research. So, contrastive analysis is a linguistic strategy for language teaching.

The theory is often criticized for being too predictive and incapability of differentiating between errors and mistakes in language learning.

\section{Analysis of English and Igbo Denominal Nouns}

Here, our focus is to assemble all the relevant bits and pieces of evidence and facts from the literature review and the contrastive study research work, present them and base our analysis on them.

Modes of formation of Igbo Denominal nouns 
1) By the use of agentive prefix "o"/ " $q$ " Eg. $\quad q k x-q k x$ aka

$\begin{array}{ll}\text { qgwq - } & \text { qgwq qr [a } \\ \text { qgba - } & \text { qgba qsq } \\ \text { qkwa - } & \text { qkwa nka } \\ \text { oti - } & \text { oti [gba } \\ \text { qbx - } & \text { qbx abx }\end{array}$

2) By the use of instrumental prefix ' $n$ '

Eg. nche - nchedo (sun protector)

ngx - ngxqnx (counter)

ntx - ntx oyi (air conditioner)

nde - nde akwa (iron)

nku - nku ikuku (fan)

nti - nti mkpu (exclaimer)

3) By the use of negativising prefix " $e$ "

Eg. eje - eje nkx (who does fetch firewood)

$\begin{aligned} & \text { eri - } \text { eri nri (non food eater) } \\ & \text { echu - } \text { echu mmiri (non fetcher } \\ & \text { of water) } \\ & \text { eje - eje eje (non-mover) } \\ & \text { eje - } \text { eje qrx (non worker) }\end{aligned}$

4) By the use of syllable reduction anya + anwx- anyanwx (sun) $\operatorname{ag} x+x l q-$ agxlq (wallgecko)

$q n x+x z q-$ qnxzq (door)

$\mathrm{xlq}+\mathrm{qrx} \quad-\quad \mathrm{xlqrx}$ (office)

onye $+[\mathrm{bq}-$ onyibq (2nd person) 
5) By the use of noun agent and noun object ode + akwxkwq - ode akwxkwq (secretary)

ogbu + anx - ogbu anx (butcher)

oji + ego - oji ego (treasurer)

nd $[+$ ah $[a-$ nd $[$ ah [a (marketers)

$\mathrm{di}+\mathrm{nta} \quad-$ dinta (hunter)

$\mathrm{di}+\mathrm{qgx} \quad-$ diqgx (fighter)

$x m x+a z x-\operatorname{xmxazx}$ (disciples)

6) By interfixation
$\operatorname{ag} x-m-\operatorname{ag} x-$
$\operatorname{agxmagx}$
$\operatorname{arx}-m-\operatorname{arx}-\operatorname{arxmarx}$
eri - m - eri - erimeri

The Modes of Formation of English Denominal Nouns

1) By prefixation

$\begin{array}{lll}\text { possibility } & - & \text { impossibility } \\ \text { sensitivity } & - & \text { insensitivity } \\ \text { cash } & - & \text { encashment } \\ \text { closure } & - & \text { enclosure } \\ \text { compass } & - & \text { encompass } \\ \text { courage } & - & \text { encouragement } \\ \text { case } & - & \text { encasement } \\ \text { construction } & - & \text { deconstruction } \\ \text { classification } & - & \text { declassification } \\ \text { register } & - & \text { deregister } \\ \text { mystify } & - & \text { demystify } \\ \text { engagement } & - & \text { disengagement } \\ \text { agreement } & - & \text { disagreement } \\ \text { appointment } & - & \text { disappointment }\end{array}$


appearance

athlete

2) by suffixation

destruction -

desk

desk

class

class

class

base

shop

map

set

child

woman

man

neighbour

bag

mile

bond

person

king

martyr

category

identity

sediments

code

predicate

intent

content
- disappearance

- decathlete

destructiveness

desktop

desk clerk

classroom

classmate

class struggle

basement

shopping

mapping

setting

childhood

womanhood

manhood

neighbourhood

baggage

mileage

bondage

personage

kingdom

martyrdom

categorization

identification

sedimentation

codification

predication

intention

contentment 


$\begin{array}{lll}\text { football } & - & \text { footballer } \\ \text { bicycle } & - & \text { bicycler } \\ \text { village } & - & \text { villager } \\ \text { nixon } & - & \text { nixonute }\end{array}$

\section{Summary of Findings and Conclusion}

It is in this section that we have to tie all the knots together and draw some inferences based on the findings of the study.

\section{Findings}

The findings of this study, expectedly, fall in line with the normal pattern of contrastive studies. That is to say, there are two sides to it - the similarities and differences. In terms of similarities, the study finds out that both English and Igbo use prefixation and suffixation, even though the ways they are used vary. In the area differences, Igbo language, unlike English, is discovered to make a wide use of syllable reduction and noun-agent and noun-object combination in the generation of Denominal nouns.

The most significant aspect of these findings is how they can be used to bring about improvement in the pedagogical approaches or methods, as they pertain to language teaching. The similarities, which have to do with prefixation and suffixation, will not obviously pose any problem to the Igbo learner of English language as the target language. The reason is because the Igbo learner is already used to those two morphological processes in their formation of nouns and nominals from nouns. 
The area that is found to overtly demand more serious attention in syllabus and curriculum planning, plus pedagogical modifications is the differences. The reason is because there is no syllable reduction, reduplication or noun-agent and noun-object concatenation in the formation of English Denominal nouns. It is highly advisable that the pedagogical efforts for the Igbo-L2 learner of English Denominal nouns be made to concentrate on the remarking and recognition of the different forms of affixes that apply to different English words in both prefixation and suffixation processes. Such an Igbo learner should be made to be conversant with the irregularities in morphological process of English Denominal nouns as opposed to that of the Igbo language.

\section{Conclusion}

The subject matter of this research has been the contrastive study of English and Igbo Denominal nouns. One of the objectives of the study has been to find out the similarities and differences in the morphological process of Denominal nouns in both languages. Another prompting factor of the investigation is to establish how the findings will help an Igbo learner of English as a second language to have less difficulty in the exercise.

The significance of these is accentuated by the fact that English language is the official language of Nigeria presently. The study has succeeded in realizing these motivations. The expectation is that if the educationists in the ministry of education do their jobs well, especially in pedagogic designs, including the printing of books, devising of the right curriculum and other measures, it will go a long way in improving the learning of the English language by the Igbo learner. The Igbo learners will be better placed in their 
English language education. The teachers will also find their job in this area easy-going.

\author{
Aloysius U. Umeodinka \\ \& Christian E. C. Ogwudile \\ Nnamdi Azikiwe University, Awka \\ aloyudo@yahoo.co.uk \\ cec.ogwudile@unizik.edu.ng
}

\title{
References
}

Agbedo, C. U. (2015). General Linguistics: Historical \& Contemporary Perspectives. Nsukka: Kurncee-Ntaeshe Press.

Anagbogu, P. N., Mbah, B. M. \& Eme, C. A. (2010). Introduction to Linguistics. Awka: Amaka Dreams Ltd.

Anozie, C. C. (2007). General Linguistics: An Introduction. Enugu: Tashiwa Network.

Bloch, B. and Trager, G. L. (1942). Outline of Linguistic Analysis. Baltimore: Waverly Press.

Crystal, D. (1969). What is Linguistics? London: Edward Arnold.

Crystal, D. (1991). A Dictionary of Linguistics and Phonetics. Oxford: Basil Blackwell Ltd.

Emenanjo, E. N. (2015). A Grammar of Contemporary Igbo (Student Edition). PortHarcourt: M\&J Grand Orbit Communication.

Finch, G. (2000). Linguistic Terms and Concepts. Hampshire: Palgrave Macmillan.

Mekiliuwa, O. (2008). An Introduction to Applied English Linguistics. Shomolu-Lagos: Fordson Part \& Sons.

Murthy, J. D. (2007). Contemporary English Grammar. Surulere-

Lagos: Bookmaster. 
Okolo, B. A. \& Ezikeojiaku, P. A. (1999). Introduction to Language and Linguistics. PortHarcourt: Swiray Publications Ltd.

Okorji, R. I. \& Okeke, C. O. (2009). "The effects of the differences between the sound systems of English and Igbo on the effective learning of English in Nigerian Schools" NKOA (Nkuzi Qmxmx Asxsx), Vol. 2.

Oluikpe, B. O. A. (1978). English in Igbo land. Onitsha: Africana Publishers Ltd.

Otagburu, E. J., Okwor, E. O., Ngonebu, C. L., Orabueze, F. O. and Ogenyi, L. C. (2012). Basic Grammar \& Composition Course for University Students. Enugu: Snaap Press Nigeria Ltd.

Prasad, T. (2014). A Course in Linguistics. Delhi: PHI Learning Private Ltd.

Lado, R. (1957). Linguistics across Cultures. Ann Arbor: University of Michigan.

Sapir, E. (1921). Language: An Introduction to the Study of Speech. New York: Harcoure Brace and World.

Schmitt, N. (Ed.) (2002). An Introduction to Applied Linguistics. London: Hodder Arnold.

Umaru, F. C. (2005). Issues in Applied English Linguistics. Nsukka: Chuka Educational Publishers.

Unpublished Work, Enumeration of English and Igbo Denominal Nouns - A Class Assignment by Onwuka Chiamaka, Obiogbolu Chononso, Ogugua Jacinta and Onuekwusi Lilian, Department of Igbo, African \& Asian Studies, Nnamdi Azikiwe University, Awka.

Wilkins, D. A. (1972). Linguistics in Language Teaching. London: Edward Arnold. 